\title{
Alternative nursery propagation for vineyards establishment
}

\author{
A. Pisciotta, G. Fazio, M.G. Barbagallo and R. Di Lorenzo \\ Department Agriculture and Forestry Sciences, University of Palermo, Viale delle Scienze, 11 Ed. 4, Ing. H, 90128 \\ Palermo, Italy.
}

\begin{abstract}
Dead vines are often a problem present in many vineyards and are due to physiological or pathological causes whereby the vines need to be replaced. The aim of the trial was to create in the nursery plant material of four cultivars in order to easily replace the dead vines in the vineyards but also to anticipate the first harvest and to improve the vineyard uniformity and synchronize the vineyard management practices during the first two years of plantation. During the first year in the nursery, the effect of plant density on the percentage of success and vegetative growth was evaluated. During the second year, in the open field and only for one cultivar, the vegetative and reproductive parameters were evaluated in vines with or without bunches. Results in the nursery showed that the row spacing did not affect nursery success. Only the cultivars showed significant effects. Instead, plant density influenced the stock and shoot diameters that were increased by the widest in-row spacing. Results in the field showed that bunch removal affected shoot elongation, daily shoot growth, stem diameter, pruning mass and root mass. Yield was strongly related with the nursery shoot diameter. Crop load affected root mass.
\end{abstract}

Keywords: nursery, new plantation, vineyard uniformity, replacement of dead vines, plant material, root development

\section{INTRODUCTION}

Dead vines are often a problem in many vineyards and are due to physiological or pathological causes (Andreini et al., 2014) whereby the vines need to be replaced. The replacement operation is a real cost due to the direct costs of the plant material, for planting and for differential management during the current year or in the two years after the replacement. Replacement also affects vineyard variability.

The vine replacement is quite easy in the first three years after vineyard establishment, but many issues occur when it is later, especially due to the root competition with older vines. It is well known that root growth and exploration can affect vegetative and reproductive parameters (Champagnol, 1984; Fregoni, 2013). The root system is partially developed in the nursery and, obviously, is affected by nursery management (in-row and inter-row distances, irrigation, etc.). Vineyard uniformity can also be supported by 1) accurate plant material selection, 2) correct vineyard establishment and management practices, and finally 3) accurate vine replacement close to vineyard establishment (Pisciotta et al., 2013). The aim of the trial was to create plant material of four cultivars in the nursery in order to 1) easily replace the dead vines in the vineyard, 2) improve the vineyard uniformity, 3) synchronize the vineyard management practices during the first two years of plantation, and 4) to anticipate the first harvest.

\section{MATERIALS AND METHODS}

- Nursery. The study was carried out during the years 2011 and 2012 in a nursery located in Marsala (TP) in western Sicily. Five different in-row distances (6-12-1824-36 cm) were used in combination with two cultivars in 2011 ('Sauvignon blanc' and 'White Muscat') and three in 2012 ('White Muscat', 'Catarratto Comune' and 'Muscat of Alexandria'). All the cultivars were grafted onto rootstock 1103P. Five 
randomized blocks per treatment (cultivar and planting distance) were imposed, with 25 vines for each block. During the vegetative season a vertical trellis system was temporarily built and one shoot was vertically trained; canopy management practices comprised of removing the basal lateral shoots and topping the primary shoot at one meter length from the grafting point. Nursery success, shoot and root length, and shoot and stem diameter were measured after uprooting.

- Field. In 2012 "new" 'Sauvignon blanc' vines were planted by a mini excavator, in a vineyard located in Petrosino (TP, western Sicily) at $2.5 \times 1.0 \mathrm{~m}$ distance and vertically trained. Before flowering (BBCH 55) (Lorenz et al., 1994), all vines were summer pruned to 3 shoots and in the thinned treatment all clusters were manually removed. During the vegetative season, in de-cropped (without bunches = DC) and cropped (with bunches $=\mathrm{C}$ ) shoots bud fertility and shoot growth were measured. At harvest quantitative parameters were evaluated. During winter pruning mass and root length were measured. Roots were classified in different classes, i.e., fine $(<3 \mathrm{~mm})$, medium $(3-6 \mathrm{~mm})$ and thick $(>6 \mathrm{~mm})$, and percentage per root category was calculated. Finally, aboveground vs. belowground plant part ratio was calculated.

The experimental design consisted of 5 completely randomized blocks per treatment with 10 vines per block. For the nursery data set, two-way (cultivar and plant density) analysis of variance (ANOVA) was applied to test for significant differences in grafting success percentage and the existence of interaction between factors. For the field data set, one-way analysis of variance and Tukey's HSD test were used to test mean differences between de-cropped and cropped vines. Analysis of variance (ANOVA) and Tukey's HSD test were used at a $5 \%$ level of significance $(\alpha=0.05)$. Lowercase letters indicate statistically significant differences at a $5 \%$ level of significance. All statistical analyses were performed using SYSTAT 10.

\section{RESULTS AND DISCUSSION}

- Nursery. Nursery success was not affected by plant density, but only by cultivar (Table 1). Particularly, 'White Muscat' and 'Catarratto Comune' seemed to have the highest success (Table 2). Stock and shoot diameters were affected by plant density (Hunter, 1998a, b), showing a significant linear regression with in-row distances in Figures 1 and 2 (Pastena, 1990). Distances of 36 or $24 \mathrm{~cm}$ seemed the most recommendable distances to obtain vigorous vines in the nursery, but more tillage and fertilization are required, thus becoming non-profitable for the nursery. Practically, a distance of $18 \mathrm{~cm}$ between stocks seemed the most suitable compromise.

Table 1. Effect of cultivar and plant density on nursery success (\%).

\begin{tabular}{|c|c|c|}
\hline Year & 2011 & 2012 \\
\hline Cultivar (2-3) & $* *$ & ${ }^{*}$ \\
\hline Plant density (5) & n.s. & n.s. \\
\hline$C \times D$ & n.s. & n.s. \\
\hline
\end{tabular}

Table 2. Mean of nursery success in the two years.

\begin{tabular}{|c|c|c|c|c|}
\hline \multirow{2}{*}{ Cultivar } & \multicolumn{2}{|c|}{2011} & \multicolumn{2}{|c|}{2012} \\
\hline & & \pm s.e. & & ts.e. \\
\hline Sauvignon blanc & $48.3 b$ & 2.6 & - & - \\
\hline White Muscat & $81.5 \mathrm{a}$ & 2.2 & $84.4 \mathrm{a}$ & 4.4 \\
\hline Catarratto Comune & - & - & $90 a$ & 2.8 \\
\hline Muscat of Alexandria & - & - & $73.3 b$ & 3.0 \\
\hline
\end{tabular}




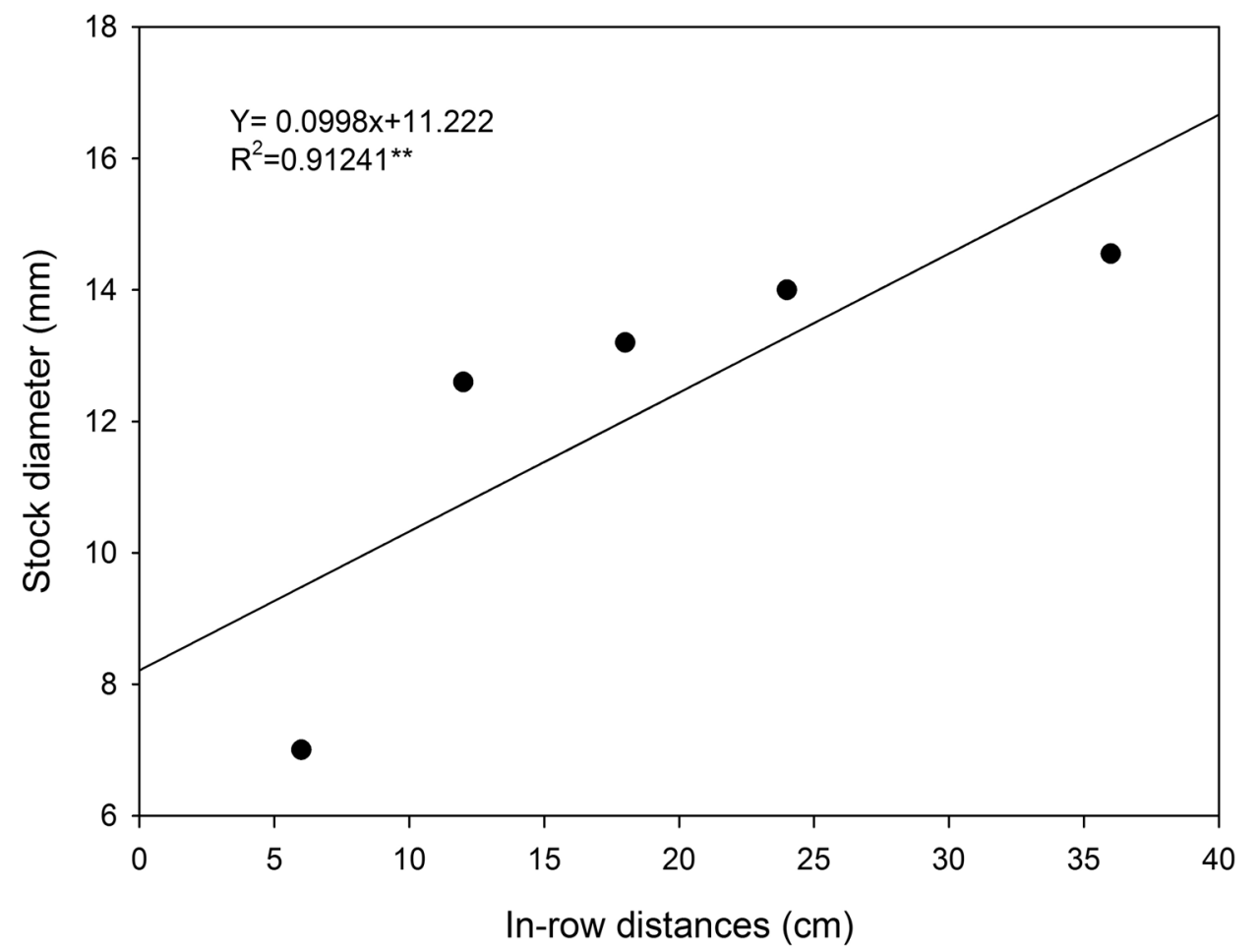

Figure 1. Linear regression between stock diameter measured in the nursery and in-row distances.

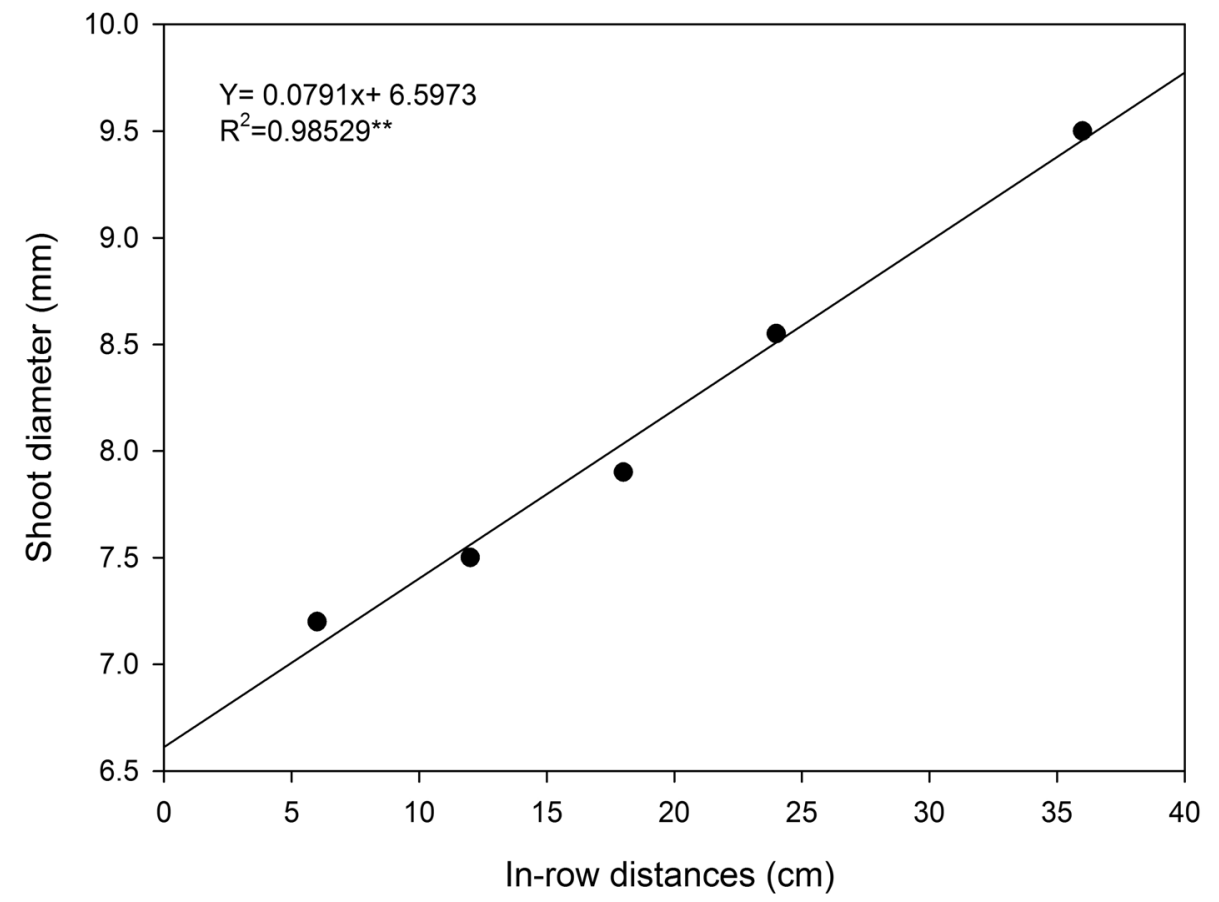

Figure 2. Linear regression between shoot diameter measured in the nursery and in-row distances. 
- Field. Using a mini excavator vines were planted in less than one minute. From 7 to 56 days after cluster thinning, a higher daily shoot growth was recorded in the decropped shoots up to harvest (Figure 3). Similar values were recorded between treatments. According to these results, differences in terms of shoot length between de-cropped and cropped shoots were recorded from 28 days after treatment until harvest (Figure 4). It is well known that a low crop load can modify the vegetative activity of vines and increase the shoot and vine vigor (Intrigliolo and Castel, 2011; Pastena, 1990). In our study, higher values of stem diameter, pruning mass and root length and mass were recorded in de-cropped shoots (Tables 3 and 4). In 2013, bud fertility was not affected by de-cropping executed in 2012, but a strong decrease in values was recorded in 2013 compared to 2012 (Table 4). In 2012, at the end of the vegetative cycle, all vines of both treatments were characterized by low vigor (Tables 3 and 4) that probably affected bud fertility negatively in the 2013 season.

Table 3. Effect of crop load on vegetative parameters.

\begin{tabular}{lccccccc}
\hline Treatment & $\begin{array}{c}\text { Stem diameter } \\
\text { (under grafting point) } \\
(\mathbf{c m})\end{array}$ & $\begin{array}{c}\text { Stem } \\
\text { FW } \\
(\mathbf{g})\end{array}$ & $\begin{array}{c}\text { Stem diameter } \\
\text { (at 70 cm above } \\
\text { grafting point) } \\
(\mathbf{c m})\end{array}$ & $\begin{array}{c}\text { Shoot } \\
\text { length } \\
(\mathbf{c m})\end{array}$ & $\begin{array}{c}\text { Shoot } \\
\text { FW } \\
(\mathbf{g})\end{array}$ & $\begin{array}{c}\text { Root length } \\
\text { profile } \\
(\mathbf{c m})\end{array}$ & $\begin{array}{c}\text { Cane } \\
\text { FW } \\
(\mathbf{g})\end{array}$ \\
\hline Cropped & $16.4 \mathrm{~b}$ & $98.2 \mathrm{~b}$ & $8.7 \mathrm{~b}$ & $55.7 \mathrm{~b}$ & $97.0 \mathrm{~b}$ & $86 \mathrm{~b}$ & $9.1 \mathrm{~b}$ \\
De-cropped & $19.7 \mathrm{a}$ & $147 \mathrm{a}$ & $13.9 \mathrm{a}$ & $87.0 \mathrm{a}$ & $143.0 \mathrm{a}$ & $119 \mathrm{a}$ & $19.6 \mathrm{a}$ \\
\hline
\end{tabular}

Means followed by a different small letter are significantly different at $a=0.05$ (HSD Tukey's test).

Table 4. Effect of crop load on vegetative, quantitative parameters and bud fertility during 2 years.

\begin{tabular}{lcccc}
\hline Treatment & $\begin{array}{c}\text { Pruning mass } \\
\text { (g) }\end{array}$ & $\begin{array}{c}\text { yield } \\
\text { (g) }\end{array}$ & $\begin{array}{c}\text { Bud fertility 2012 } \\
\left.\text { (Bunch shoot }^{-1}\right)\end{array}$ & $\begin{array}{c}\text { Bud fertility 2013 } \\
\text { (Bunch shoot }^{-1} \text { ) }\end{array}$ \\
\hline Cropped & 99.5 & 578 & 1.3 & 0.54 \\
De-cropped & $180.8 \mathrm{a}$ & - & 1.3 n.s. & 0.54 n.s. \\
\hline
\end{tabular}

Means followed by a different small letter are significantly different at $\alpha=0.05$ (HSD Tukey's test). n.s. =not significant.

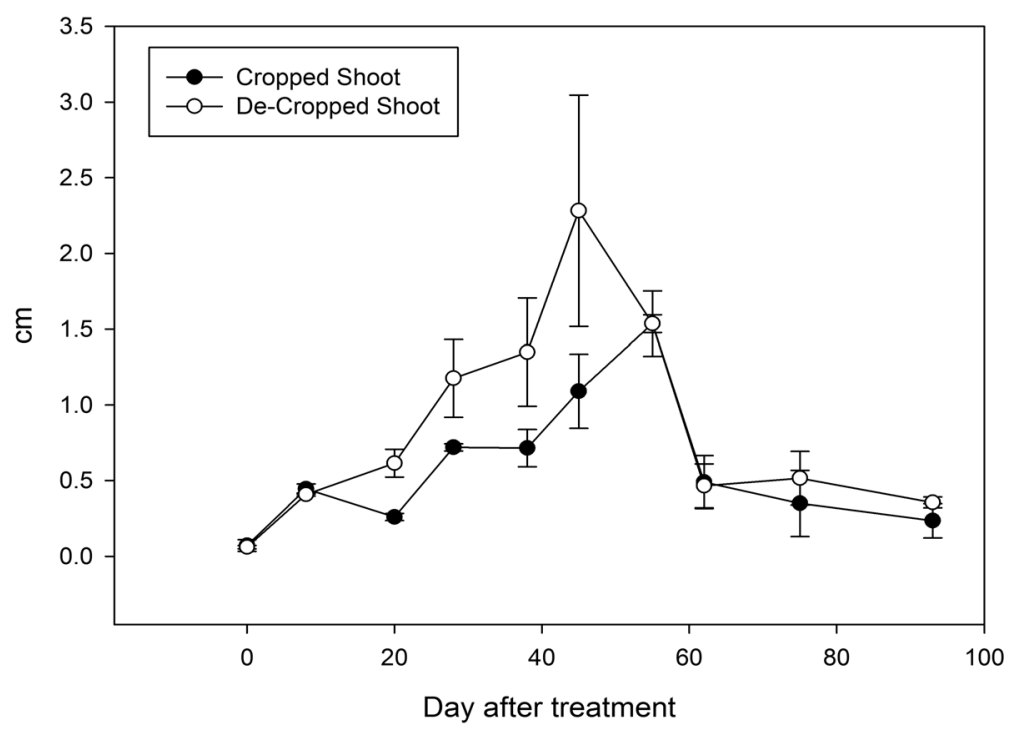

Figure 3. Daily shoot growth of de-cropped and cropped shoots. Vertical bars represent standard errors. 


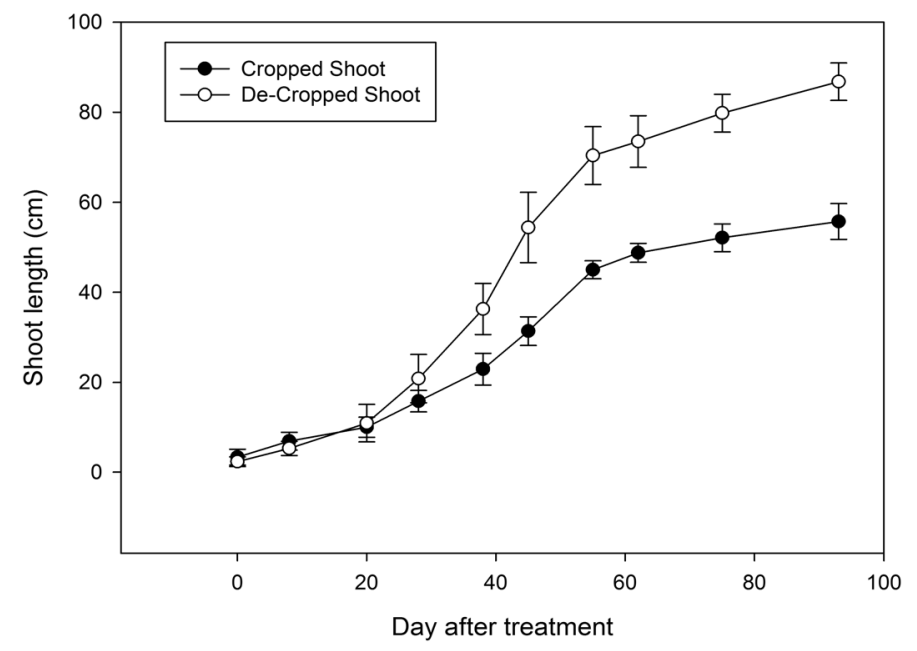

Figure 4. Shoot growth of de-cropped and cropped shoots. Vertical bars represent standard errors.

Yield was strongly correlated with the plant vigour (shoot diameter) obtained in the nursery (Figure 5) and crop load affected root mass (Table 5) (Lakso and Eissenstat, 2005). Presence of medium roots (3-6 mm) was recorded in both treatments. Vines with bunches showed a root system with more fine roots, while the vines without bunches had a higher number of medium and large roots. In the cropped vines, the same incidence of fine and medium roots was found (38.9 and $42.7 \%$, respectively), whereas in the de-cropped plants this was found for fine and large roots (25.6 and 24.0\%, respectively). Moreover, fine root percentage and total roots mass (Table 5) showed the main difference between cropped and de-cropped vines. Early canopy development (i.e., larger leaf area) in spring promotes early root growth; thus, root growth of de-cropped vines peaks earlier than that of cropped vines. The total root biomass increases from growth of permanent roots in length and diameter throughout the growing season from shortly after budbreak until leaf fall in both young and mature vines (Araujo and Williams, 1988; Williams and Biscay, 1991). However, most of the fine roots (less than $1 \mathrm{~mm}$ in diameter) which are the vine's major water and nutrient absorbing structures, are short lived, so they have to be replaced continuously, probably because the soil around them quickly becomes exhausted (Comas et al., 2000, 2010). Only a few of them live longer and, through secondary growth, may eventually become large, structural roots. Fine roots produced before bloom have an extremely short life span compared with those produced later in the growing season (Anderson et al., 2003). Maybe an increase in fine root in cropped vines, can be considered a response to restore the root:shoot ratio to a balance that is more favourable for a growth (Bloom et al., 1985) and generally to support its crop.

The aboveground vs. belowground plant part ratio highlights how the de-cropped vines balanced the growth between the two parts $(\mathrm{E} / \mathrm{I}=1.1)$, while the cropped vines developed a stronger aerial part $(\mathrm{E} / \mathrm{I}=1.7)$, reducing root development (Table 5).

Table 5. Effect of crop load on root characteristics (on total mass basis), total roots mass and aboveground: belowground ratio (E/I).

\begin{tabular}{|c|c|c|c|c|c|}
\hline \multirow[t]{2}{*}{ Treatment } & \multicolumn{3}{|c|}{$\begin{array}{c}\text { Root distribution (\%) } \\
\text { (total mass basis) }\end{array}$} & \multirow{2}{*}{$\begin{array}{c}\text { Total } \\
\text { mass } \\
\text { (g) }\end{array}$} & \multirow[t]{2}{*}{ E/l } \\
\hline & $<3 \mathrm{~mm}$ & $3-6 \mathrm{~mm}$ & $>6 \mathrm{~mm}$ & & \\
\hline Cropped & $38.9 \mathrm{a}$ & $42.7 \mathrm{~b}$ & $18.3 \mathrm{~b}$ & $131 \mathrm{~b}$ & $1.7 \mathrm{a}$ \\
\hline De-cropped & $26.6 \mathrm{~b}$ & $48.4 \mathrm{a}$ & $25.0 \mathrm{a}$ & $300 a$ & $1.1 \mathrm{~b}$ \\
\hline
\end{tabular}

Means followed by a different small letter are significantly different at $a=0.05$ (HSD Tukey's test). n.s.=not significant. 


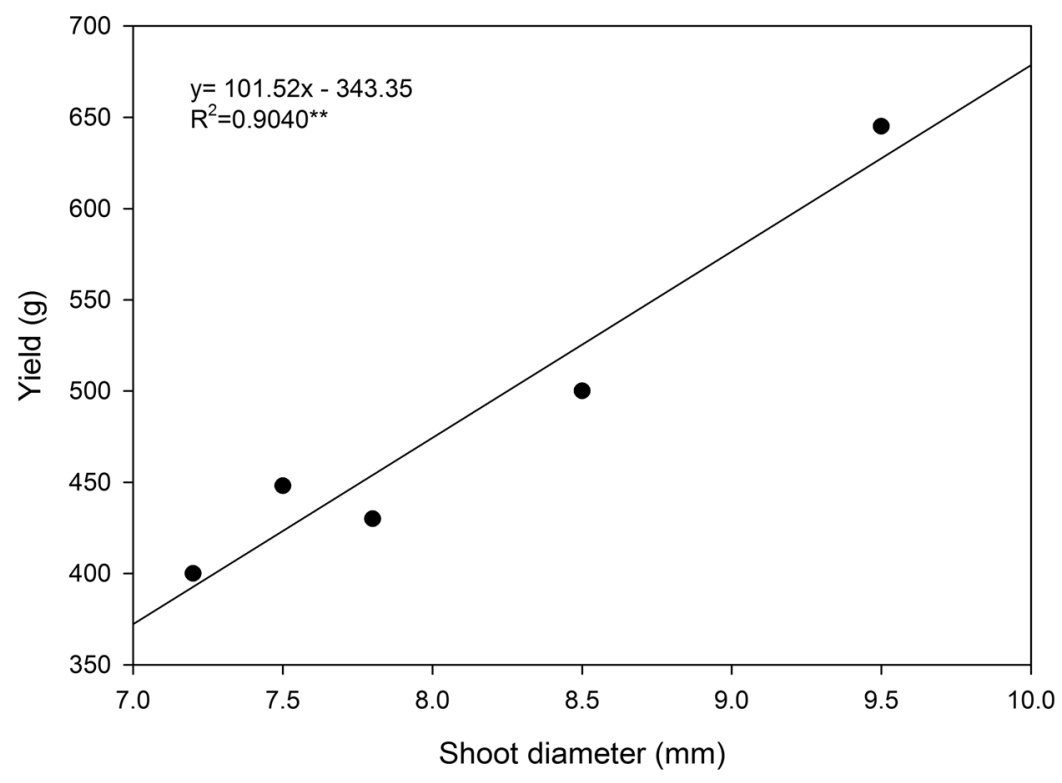

Figure 5. Linear regression between yield and shoot diameter.

\section{CONCLUSIONS}

The nursery propagated plants can be used in a new vineyard establishment and can reduce the vineyard variability when dead vines must be replaced. Vineyard management during the training period can be facilitated. The first production can be easily obtained in the year of plantation under vigorous conditions, but a judicious vine selection from the nursery is necessary. A yield reduction in the next season should under any circumstances be anticipated.

\section{ACKNOWLEDGEMENTS} advice.

Thanks to "Vivai Mannone" Nursery and their technicians for assistance and technical

\section{Literature cited}

Anderson, L.J., Comas, L.H., Lakso, A.N., and Eissenstat, D.M. (2003). Multiple risk factors in root survivorship: a 4 year study in Concord grape. New Phytol. 158 (3), 489-501 http://dx.doi.org/10.1046/j.1469-8137.2003. 00757.x.

Andreini, L., Cardelli, R., Bartolini, S., Scalabrelli, G., and Viti, R. (2014). Esca symptoms appearance in Vitis vinifera L.: influence of climate, pedo-climatic conditions and rootstock/cultivar combination. Vitis 53, 33-38.

Araujo, F.J., and Williams, L.E. (1988). Dry matter and nitrogen partitioning and root growth of young field-grown Thompson Seedless grapevine. Vitis 27, 21-32.

Bloom, A.J., Chapin, F.S., III, and Mooney, H.A. (1985). Resource limitation in plants: an economic analogy. Annu. Rev. Ecol. Syst. 16 (1), 363-392 http://dx.doi.org/10.1146/annurev.es.16.110185.002051.

Champagnol, F. (1984). Element de Physiologie de la Vigne et de la Viticolture Generale (Montpellier, France: Dehan), pp.351.

Comas, L.H., Eissenstat, D.M., and Lakso, A.N. (2000). Assessing root death and root system dynamics in a study of grape canopy pruning. New Phytol. 147 (1), 171-178 http://dx.doi.org/10.1046/j.1469-8137.2000.00679.x.

Comas, L.H., Bauerle, T.L., and Eissenstat, D.M. (2010). Biological and environmental factors controlling root dynamics and function: effects of root ageing and soil moisture. Aust. J. Grape Wine Res. 16, 131-137 http://dx.doi.org/10.1111/j.1755-0238.2009.00078.x.

Fregoni, M. (2013.) Viticoltura di Qualità. Trattato di Eccellenza del Terroir. III edn (Milano, Italy: Tecniche Nuove), pp. 939.

Hunter, J.J. (1998a). Plant spacing implications for grafted grapevine I. Soil characteristics, root growth, dry 
matter partitioning, dry matter composition and soil utilization. S. Afr. J. Enol. Vitic. 19 (2), 25-34.

Hunter, J.J. (1998b). Plant spacing implications for grafted grapevine II. Soil water, plant water relations, canopy physiology, vegetative and reproductive characteristics, grape composition, wine quality and labour requirements. S. Afr. J. Enol. Vitic. 19 (2), 35-51.

Intrigliolo, D.S., and Castel, J.R. (2011). Interactive effects of deficit irrigation and shoot and cluster thinning on grapevine cv. Tempranillo. Water relations, vine performance and berry and wine composition. Irrig. Sci. 29 (6), 443-454 http://dx.doi.org/10.1007/s00271-010-0252-2.

Lakso, A.N., and Eissenstat, D.E. (2005). Crop load-physiology, modeling and relationship to root growth in grapevines. Paper presented at: $12^{\text {th }}$ Australian Wine Industry Technical Conference (Melbourne, Australia).

Lorenz, D.H., Eichhorn, K.W., Bleiholder, H., Klose, R., Meier, U., and Weber, E. (1994). Phänologische Entwicklungsstadien der Rebe (Vitis vinifera L. ssp. vinifera). Codierung und Beschreibung nach der erweiterten BBCH-Skala. Viticultural and Enological Sciences 49, 66-70.

Pastena, B. (1990). Trattato di Viticoltura Italiana (EdAgricole).

Pisciotta, A., Barbagallo, M.G., Scafidi, P., and Di Lorenzo, R. (2013). Vegetative and reproductive parameters evaluation of alternative plant material. Paper presented at: $64^{\text {th }}$ ASEV National Conference (Monterey, California, USA).

Williams, L.E., and Biscay, P.J. (1991). Partitioning of dry weight, nitrogen, and potassium in Cabernet Sauvignon grapevines from anthesis until harvest. Am. J. Enol. Vitic. 42, 113-117. 
